\title{
Vendendo saúde! Revisitando os antigos almanaques de farmácia
}

\author{
Selling health! A new look at old-time \\ pharmacy almanacs
}

Mario Luiz Gomes

Bacharel em história

Rua Divinópolis, 146, Bosque 12233-200 São José dos Campos SP - Brasil

marioluizgomes@ig.com.br
GOMES, M. L. Vendendo saúde! Revisitando os antigos almanaques de farmácia.

História, Ciências, Saúde - Manguinhos,

Rio de Janeiro, v. 13, n. 4, p. 1007-18, out.-dez. 2006.

O artigo destaca a importância dos almanaques de farmácia como fonte de pesquisa em relação à história dos medicamentos, apresentando imagens desses impressos relacionadas às estratégias de promoção dos produtos farmacêuticos. A idéia de ciência veiculada pelos almanaques de farmácia também é analisada, indicando a relevância desse tipo de fonte para a história da ciência e da propaganda no Brasil.

PALAVRAS-CHAVE: almanaques de farmácia; ciência; medicamentos.

GOMES, M. L. Selling health! A new look at old-time pharmacy almanacs.

História, Ciências, Saúde-Manguinhos,

Rio de Janeiro, v. 13, n. 4, p. 1007-18., Oct.-Dec. 2006.

Offering images of pharmaceutical products and marketing strategies, pharmacy almanacs are a valuable source when researching the history of medications. The article analyzes the idea of science that was presented in these almanacs and demonstrates how this research source is pertinent to the history both of science and of advertising in Brazil.

KEYWORDS: pharmacy almanacs; science; medicines. 
${ }^{1}$ Trata-se de um acervo que até o momento reúne cerca de 350 exemplares dos almanaques de farmácia. Estão neles representados os grandes laboratórios, nacionais e estrangeiros, as pequenas indústrias e algumas farmácias e drogarias, umas mais modestas, outras de renome - como a Granado, do Rio de Janeiro, e a Beirão, de Belém, no estado do Pará. Constitui-se em sua maioria de publicações relativas às décadas de $1930 \mathrm{e}$ 1940, quando atingiram o auge de sua qualidade e de seu número em circulação.

\section{"O almanaque, por favor"}

$\mathrm{E}$ ditados desde o século XIX, os 'almanaques de farmácia' foram publicações que durante décadas promoveram e popularizaram as drogas medicinais e os artigos cosméticos que competiam em nosso mercado de saúde. Elaborados inicialmente por algumas das antigas 'pharmacias' de manipulação, passaram posteriormente a fazer parte do conjunto de estratégias publicitárias adotadas pela maioria dos modernos laboratórios químico-farmacêuticos para a promoção e comercialização de seus produtos.

Milhões de exemplares dessas publicações foram editados e distribuídos por todo o país. Formato ágil, equilibrando seu caráter intrinsecamente comercial com o espírito e o conteúdo dos almanaques tradicionais, levou não só a populações urbanas, mas a pequenas comunidades rurais, uma possibilidade de informação e entretenimento. Para muitos, em determinadas circunstâncias e frente à carência material e cultural do meio, o almanaque representou o livro e a revistinha infantil; em outras ocasiões, assumindo caráter e função particularmente inusitados, fez a vez da própria cartilha, auxiliando adultos e crianças no aprendizado da leitura.

Adotados e adaptados dessa forma pela população, transcenderam ao simples caráter panfletário, instalando-se como hábito de leitura. Circularam durante várias décadas popularizando marcas nacionais e estrangeiras. Foram desaparecendo à medida que se sofisticavam as técnicas de propaganda e marketing.

Dos milhões de exemplares lançados pelo Brasil afora, poucos restam. Representam, atualmente, testemunhos insubstituíveis de época, e um patrimônio comum a toda nossa indústria farmacêutica.

As poucas pesquisas desenvolvidas até o momento sobre o tema são unânimes acerca das dificuldades em se estudar esse tipo de fonte, em virtude da inexistência de acervos em bibliotecas ou instituições de pesquisa. Por essa razão, as coleções particulares ganham uma dimensão essencial para o desenvolvimento de projetos que envolvem esses impressos, como é o caso do conjunto de almanaques objeto deste artigo. ${ }^{1}$

Nosso objetivo, aqui, consiste em destacar aspectos comuns a diferentes almanaques de farmácia, utilizando algumas imagens de propagandas e seções desses impressos.

\section{A propaganda}

A linguagem nos anúncios dos almanaques percorria do mau gosto intimidativo e cru à mais refinada e sutil prosa aliciante. Literatos de renome estiveram a serviço dos laboratórios farmacêuticos de maior porte. Mais que elaborar mensagens diretas e convencionais, muitos deles superavam os limites do simples texto comercial, 
explorando com criatividade a crônica e o conto, construindo enredos e personagens, sem fugir ao rigor dos objetivos e resultados práticos. Abordando temas polêmicos para a época, como divórcio e homossexualismo, ou recorrendo ao simplismo do 'antes e depois', os publicitários procuravam recriar situações que se identificassem com os problemas mais rotineiros de higiene, saúde e beleza (Figuras 1 e 2).

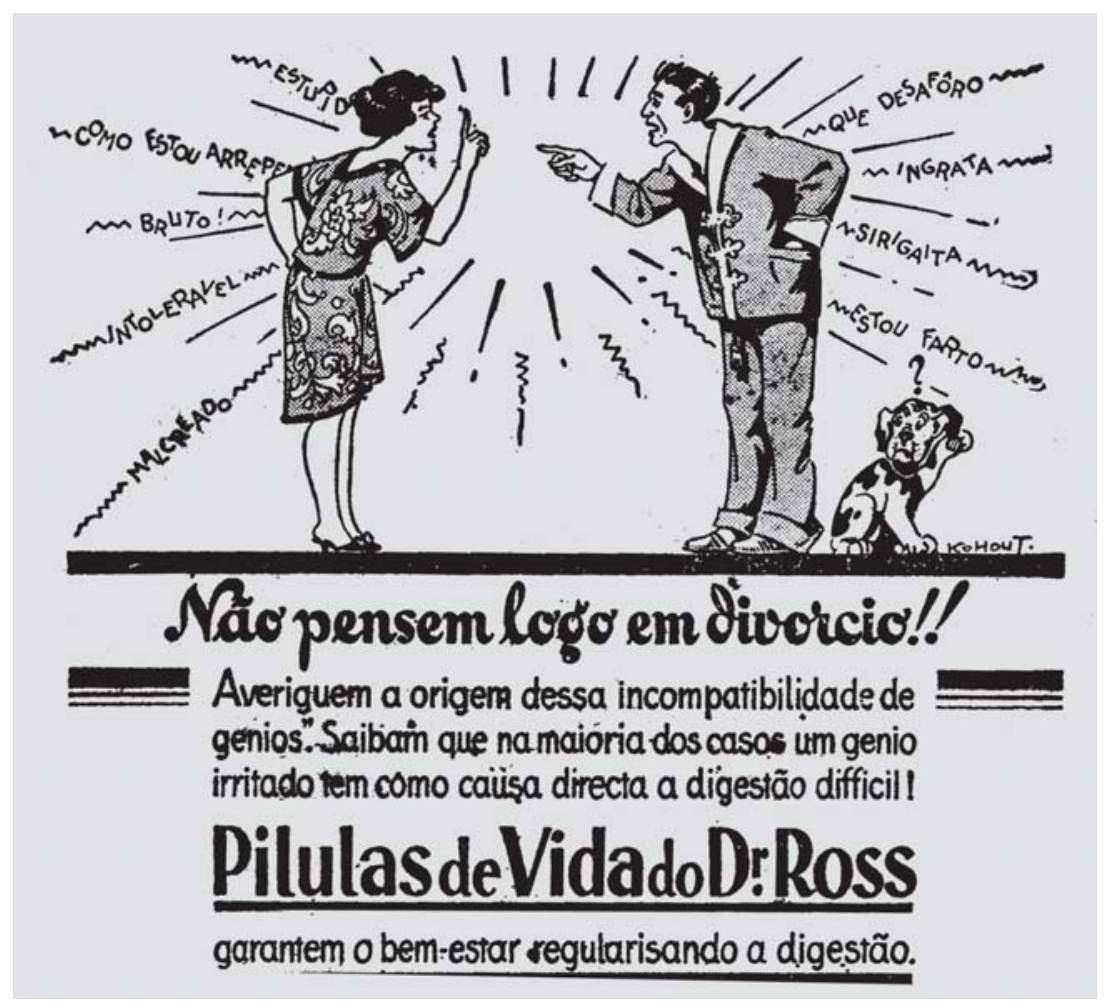

Figura 1 - Almanach Americano de Ross, 1931, p. 30.

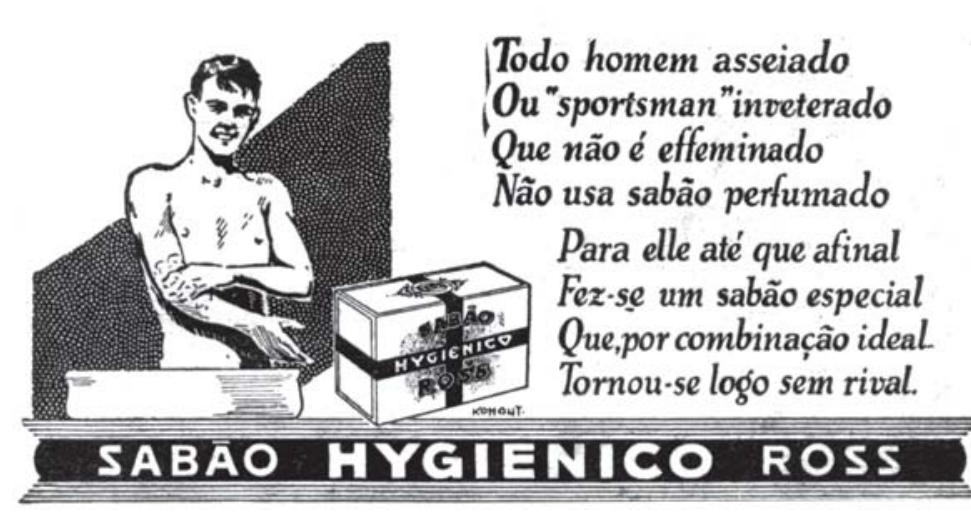

Figura 2 - Revista Almanach de Ross, 1932, p. 23. 
O discurso da propaganda, em seu aspecto mais geral, vai se empenhar em demonstrar as vantagens utilitárias da boa aparência e de um corpo saudável (Figura 3). O que seria um atributo natural passa, pela ótica publicitária, a ser considerado um prérequisito essencial para o êxito econômico e social. As promessas de cura em soluções rápidas e baratas vinham acompanhadas de sedutoras possibilidades de realização pessoal. Convencidos pela argumentação dos textos, leitores e leitoras experimentavam o xarope, a pílula ou o elixir, na esperança da gratificação física, material e sentimental.

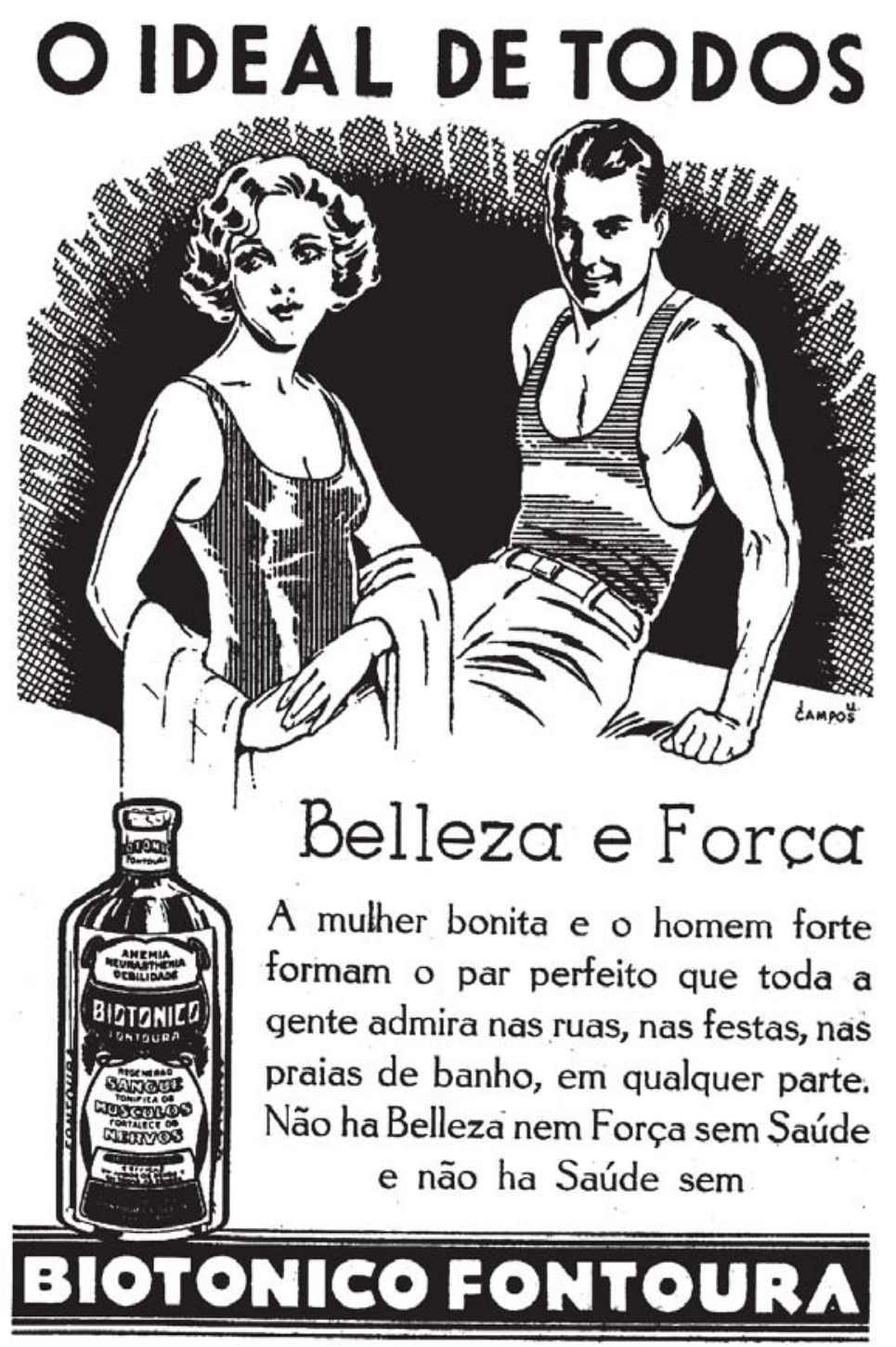

Figura 3 - Almanaque do Biotonico, 1934, p. 8. 
'Saúde é beleza' era o slogan preferido dos propagandistas. Insistentemente veiculado, instigava a vaidade e a fantasia feminina ao acenar com os (supostos) efeitos embelezadores obtidos mediante $o$ uso de determinados medicamentos. Grande parte dos anúncios principalmente sobre laxantes e reguladores - reafirmava esses pressupostos, colocando em plano privilegiado aquilo que supostamente reverteria em bons resultados exteriores. Explorado na maioria das publicações, tornou-se um clássico e uma das idéias centrais da publicidade nos almanaques.

A tarefa de implantar novos hábitos de higiene, saúde e beleza coube em boa parte aos profissionais publicistas. Seus textos e imagens (especialmente a partir da década de 1930) vão introduzir não só as novas drogas científicas, mas novos padrões de comportamento, usos e costumes. Em busca de mercado para seus produtos industriais, a propaganda dos laboratórios arremete contra o modo de vida passado, sobrepondo-se às práticas artesanais de medicina caseira e desqualificando-as. Redatores e ilustradores passam a reproduzir o clima dinâmico de uma sociedade que se transforma rapidamente. Velocidade, agilidade, a vertigem e a força de aeroplanos e automóveis são temas e símbolos que sintetizam o clima desse momento, e que sugestivamente se apresentarão cada vez mais em seus trabalhos.

A tradicional técnica dos testemunhos representou uma das formas promocionais mais utilizadas nos almanaques. Consistia na participação direta dos consumidores através de cartas enviadas aos laboratórios. Os depoimentos de cunho pessoal narravam geralmente em linguagem exageradamente dramática - os percalços em busca do remédio ideal, terminando por enaltecer os efeitos alcançados com o uso (enfim) daquele determinado produto. Repassado página a página, o forte conteúdo emocional dos discursos incentivava os leitores identificados com a situação a tentarem também a mesma experiência. $\mathrm{O}$ volume recebido (e sempre citado) desses atestados funcionava como mais um elemento de estímulo agregado à sua propaganda (Figura 4).

Percebidas como força considerável de persuasão, as palavras de médicos, artistas populares e representantes da Igreja católica compartilhavam estrategicamente os espaços publicitários nos almanaques. Reforçando as manifestações espontâneas do usuário comum, o prestígio e a credibilidade dessas fontes exerceriam influência decisiva no ato da escolha.

Quanto mais bem produzido o almanaque, maiores as suas possibilidades de aceitação e de retorno público. Investir na colaboração de escritores, poetas, humoristas e ilustradores de destaque resultou em momentos de alto nível de comunicação escrita e ilustrada. 


\section{TINITA UM TEDIO HORPIVEL...}

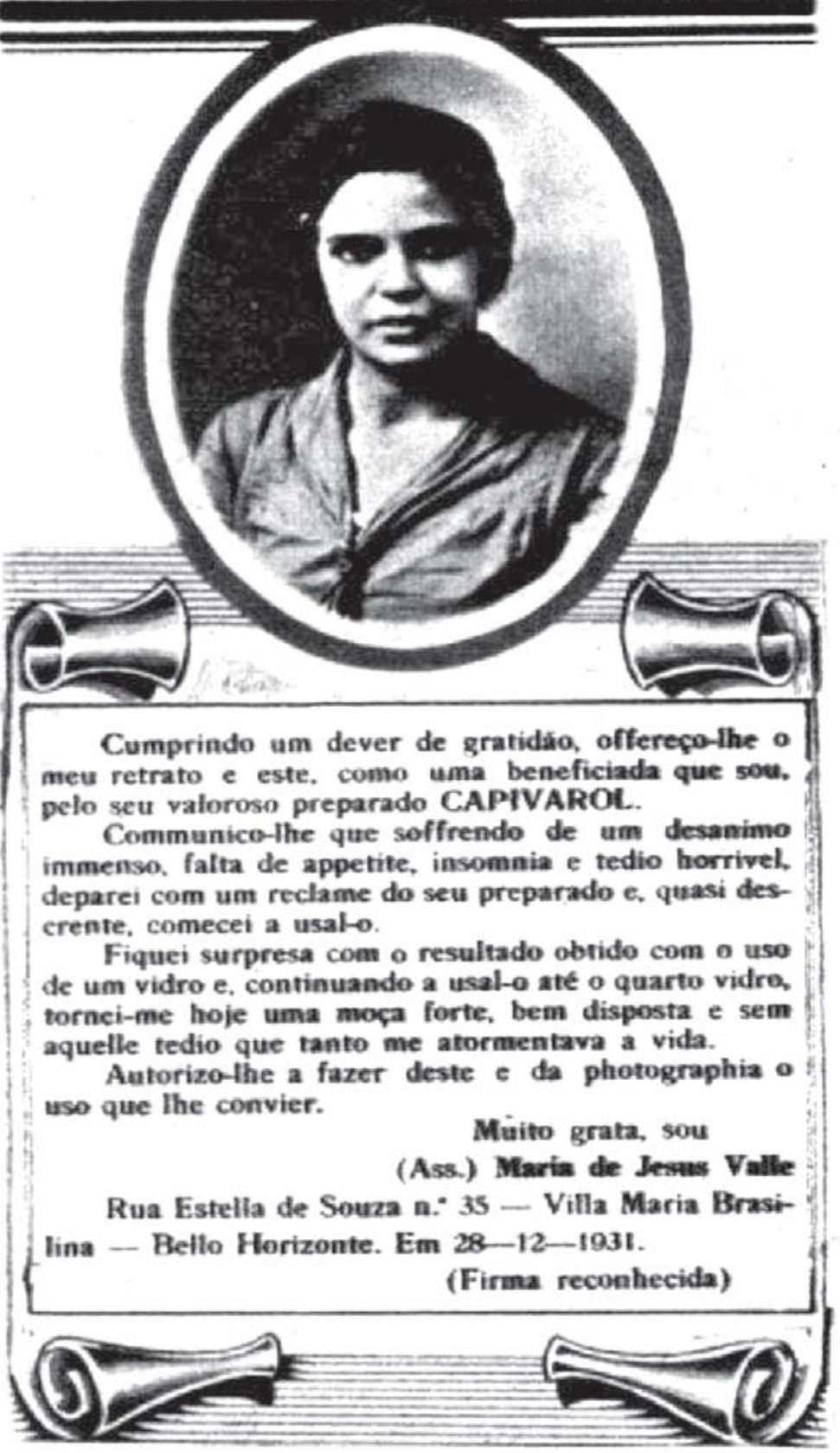

Figura 4 - Almanaque Capivarol, 1933, p.10. 


\section{Os colaboradores}

Monteiro Lobato foi o intelectual mais importante para a história da propaganda nos almanaques de farmácia. Amigo pessoal do farmacêutico e industrial Cândido Fontoura, foi o responsável pela idealização - e confecção - do exemplar inaugural (1920) do Almanach do Biotonico. Sua efetiva contribuição, porém, viria com a adaptação para a publicidade de seu controvertido personagem 'Jeca Tatuzinho'. Capitalizado para alavancar a campanha contra a verminose (promovendo a Ankilostomina e o próprio Biotônico Fontoura), foi lançado em livreto (no princípio dos anos 20), transformando-se em sucesso imediato. Nessa breve e divertida fábula sobre o progresso, a saga do homem do campo brasileiro vencendo os males da opilação, chamou a atenção e conquistou a simpatia de milhões de leitores. Em sua trigésima quinta edição (1973) alcançou um total de 84 milhões de exemplares, transformando o 'Jeca' na obra de maior divulgação em todo o Brasil.

Outras participações de Lobato (sempre nos almanaques do Biotônico) encontram-se espalhadas pelos números anuais da publicação (Figura 5). Modestas, pouco havia a acrescentar depois do fenômeno Jeca Tatu.

Menotti Del Picchia escreveu especialmente para o Almanach Rhodia de 1936, e o poeta e humorista Bastos Tigre (D. Xiquote) era presença constante em vários deles. Embora seja difícil localizá-los, outros autores de porte certamente estiveram envolvidos com os almanaques. Parte da produção escrita inserida nessas publicações

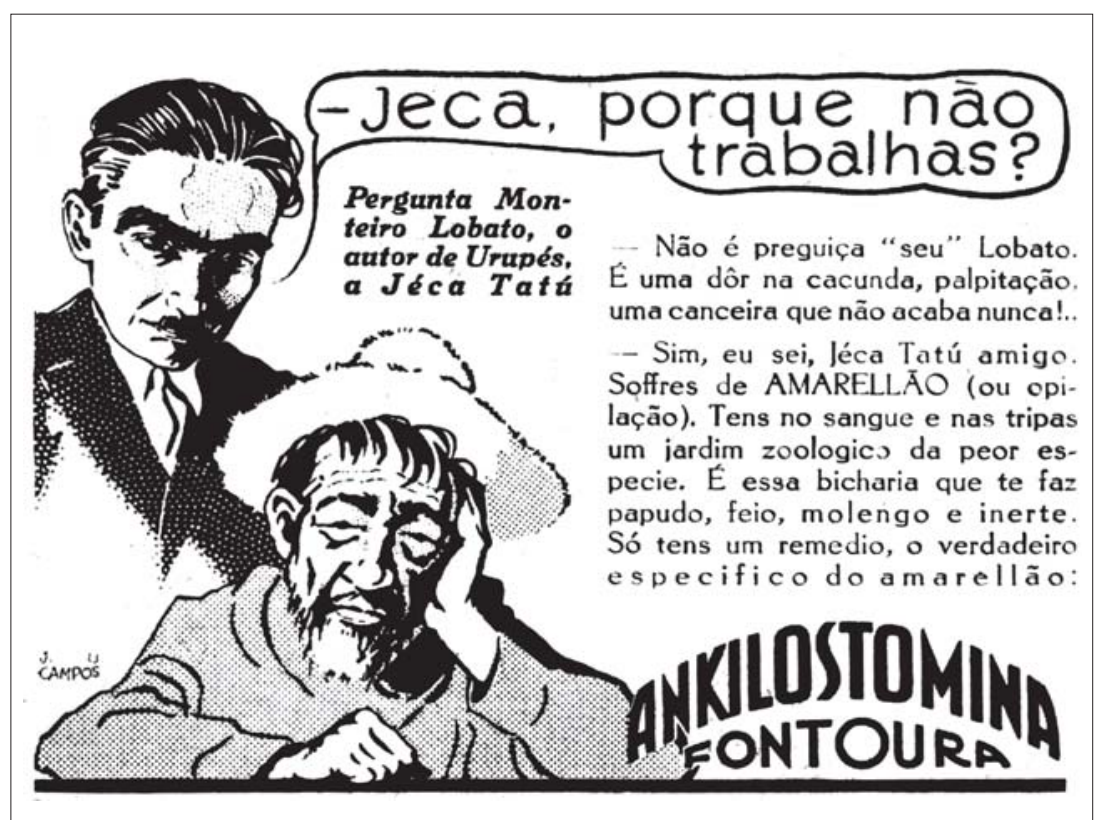

Figura 5 - Almanaque do Biotonico, 1935, p. 4 (ilustração de J. U. Campos). 
permaneceu preservada sob a discrição do anonimato. Preferiram a convivência sigilosa e a não exposição pública, num veículo prioritariamente comercial.

A ilustração nos almanaques guarda registros de alguns dos mais reconhecidos artistas do gênero. Nomes como Belmonte, Kohout (Figura 6), Raul, J. U. Campos e J. Carlos, ao lado do traço não menos famoso de Kalixto, Max Yantock, Seth e Luiz Sá, foram os responsáveis pela graça e beleza que tornavam prazerosa e divertida sua leitura.

Apresentaram casais de namorados preocupados com a sífilis (Figura 7), quadrinhos de humor, melindrosas e mulheres sensuais ao banho; traduziram em imagens a angústia da doença, a felicidade da cura, a ansiedade da competição na nova era industrial. Recriaram

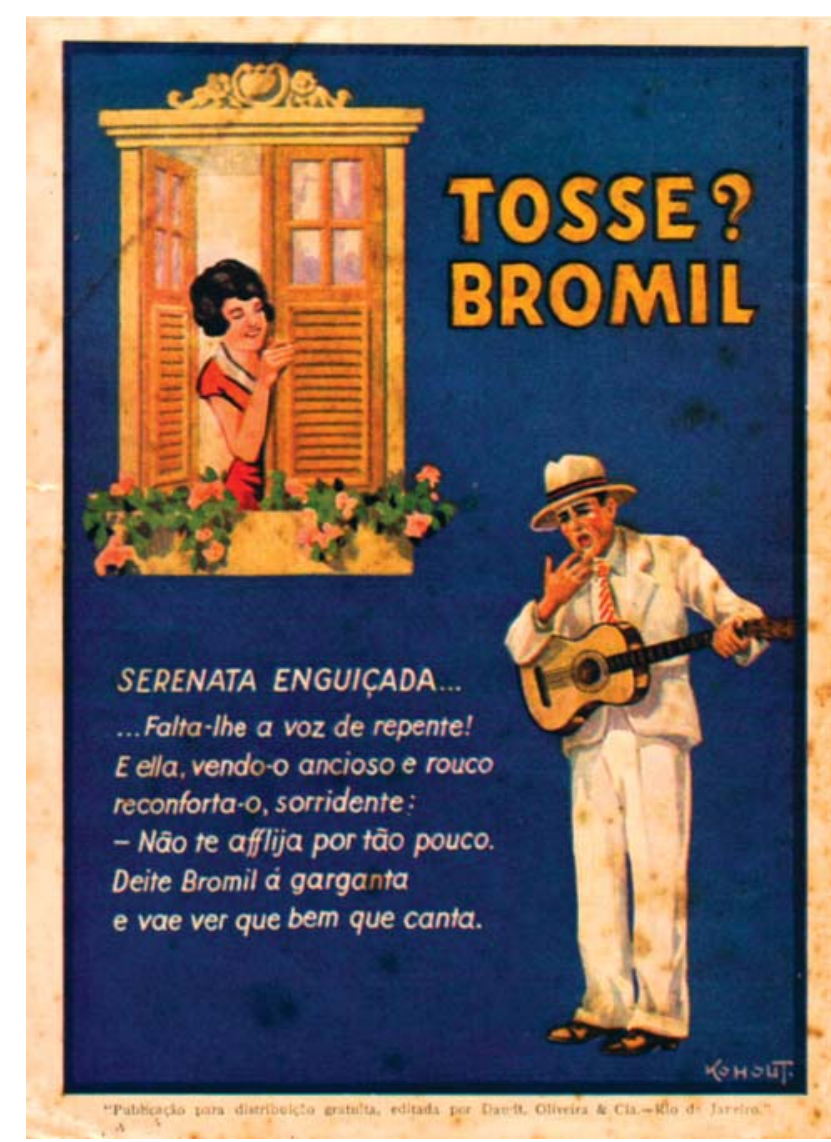

Figura 6 - contracapa do Almanach d'A Saude da Mulher, 1932 (ilustração de Franz Kohout).

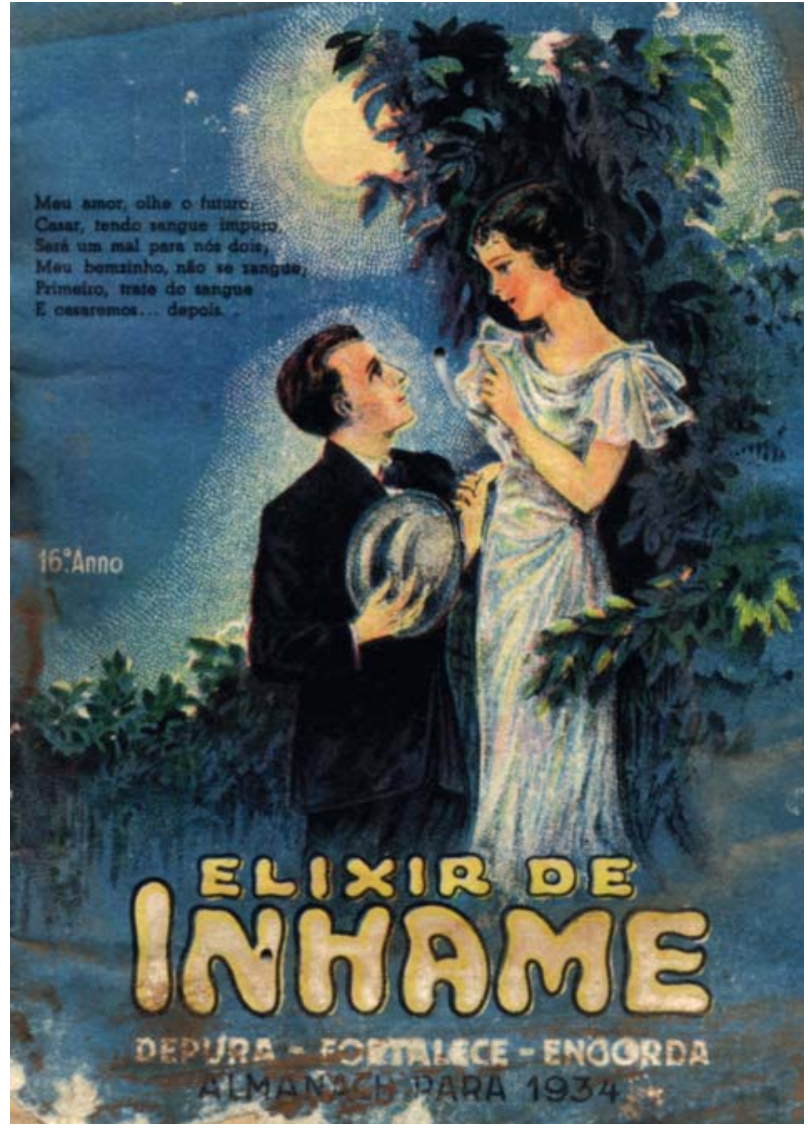

Figura 7 - capa do Almanach para 1934 do Elixir de Inhame.

"Meu amor, olhe o futuro:

Casar, tendo o sangue impuro,

Será um mal para nós dois,

Meu bemzinho, não se zangue,

Primeiro, trate do sangue

E casaremos... depois". 
do cotidiano a dor e a prostração feminina 'naqueles dias', o horror infantil diante do óleo de rícino, o carinho do gesto materno na atenção ao bebê. Revelaram para muitos o interior do corpo humano, e acompanhando a moda trouxeram para suas capas o glamour das louras estilizadas, influência direta dos estúdios de Hollywood (Figura 8).

Venderam sabonetes, remédios e idéias, intervindo diretamente nos hábitos de seus leitores.



Figura 8 - Capa do Almanaque do Biotonico, 1941. 


\section{Almanaque e ciência}

Guia doméstico de saúde, o almanaque de farmácia mais que informar sobre remédios e doenças, introduziu em termos populares uma possibilidade de iniciação científica. Seu discurso, intermediado pela linguagem da publicidade, disponibilizou para muitos, em texto e imagem, o que antes constituía um conhecimento restrito a poucos.

Segundo Vera Casa Nova (1999, p. 60),

A ciência do almanaque de farmácia, saída dos bancos de escola, é muito mais história da ciência do que ciência propriamente dita. Com ares de seriedade, a ciência (química, física, biologia e matemática) é divulgada, popularizada, através de certas práticas ensinadas para serem repetidas, freqüentemente, como lazer, em serões, em família. Diríamos, até, uma ciência caseira, uma ciência lúdica. Lazer e utilidade parecem caracterizar o almanaque de farmácia enquanto leitura popular, que ensina, brincando, a adultos e crianças.

Traduziu em ilustrações o corpo humano e suas funções, incorporou ao vocabulário cotidiano novas palavras, termos científicos que nomeavam agentes, produtos, técnicas e fórmulas. Estimulou com jogos o raciocínio, a lógica, a memória, induzindo com simplicidade a formação de um pensar racional, e de uma nova maneira de explicar o mundo. Interferiu no cotidiano, criando novos hábitos de higiene e saúde, contrapondo seus produtos industrializados, às práticas seculares de medicina caseira.

A considerarmos que os almanaques de farmácia fazem parte de nossas leituras desde o século XIX, e que foram muitas vezes os únicos a atingirem determinadas populações do país, justifica-se repensar seu significado como documento.

A tônica dos almanaques de farmácia - como não poderia deixar de ser - é a questão técnico-científica (Figuras 9 e 10). Tentam repassar ao leitor a idéia de sua importância como componente fundamental, diretamente envolvido na fatura dos produtos medicinais e, portanto, nos processos de cura ou na manutenção da saúde. Seu discurso em termos gerais depõe contra a cultura tradicional de chás, infusões e procedimentos empíricos, na tentativa de desqualificar 'o natural' e substituí-lo pela produção técnica de massa.

$\mathrm{O}$ aval de organismos e eventos oficiais (como as feiras nacionais e internacionais) era de imediato incorporado como referendo definitivo de qualidade e garantia dos produtos (Figuras 11 e 12). O alarde com que tais premiações eram divulgadas nos almanaques indica o grau de sugestão e influência que o termo 'scientífico' teria sobre o leitor. Apesar - em muitos casos - do mau uso do conceito, das inevitáveis panacéias, dos clichês publicitários e de suas intenções acima de tudo comerciais, disseminaram, de acordo com sua visão e interesses, o ideário cientificista de época. 


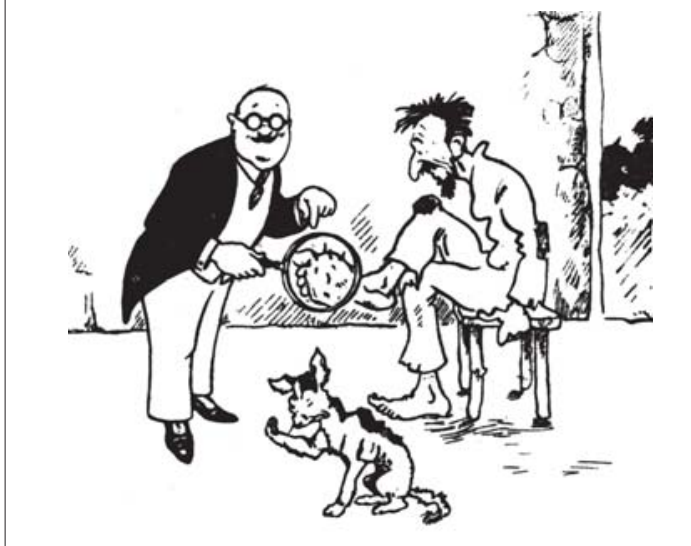

Figura 9 - Jéca Tatuzinho - edicção especial do Instituto 'Medicamenta' Fontoura Serpe \& Cia., São Paulo, Fontoura \& Serpe, 1925, p.15 (ilustração de Wiese).

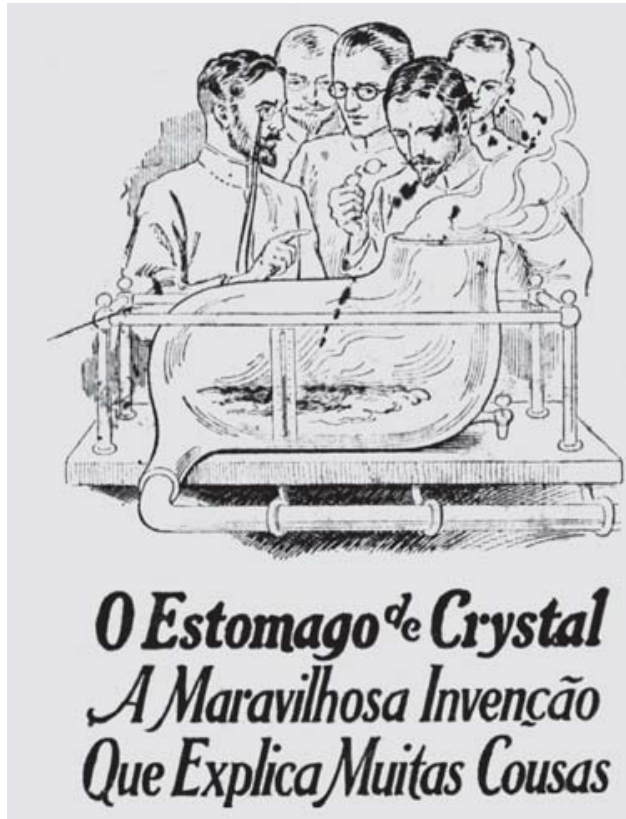

Figura 10 - capa do livreto O Estomago de Crystal. Norwalk, Conn. EUA Laboratório Dr. Richards Dyspesia Tablet Association, (1928?).

\section{DO PHARMACEUTiCo E Chimico JOA0 DA SILVA SILVEIRA \\ Approvado pela Ex.ma Junta de Hygiene do Rio de Janeiro e premiado nas Exposições de \\ Chicago 1893, Rio Grande do Sul 1901 e Nacional 1908} Figura 11 - Capa interna - Almanak Silveira para 1914.

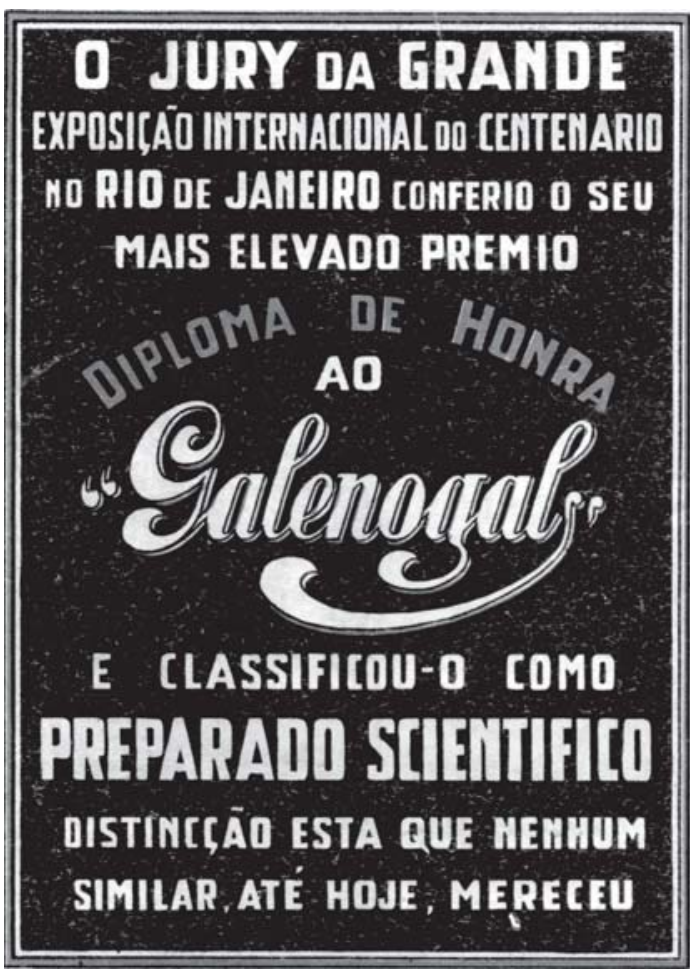

Figura 12 - Contracapa do Almanach do Galegonal, 1937.

\section{Considerações finais}

Protagonistas de um projeto que envolveu ciência, comércio e propaganda, os originais que aqui reaparecem possibilitam uma rápida incursão pelo passado daqueles que com boa-fé ou malícia aventuraram-se pelos segredos dos cadinhos e retortas em busca da melhor fórmula ou, simplesmente, do negócio mais lucrativo. 


\section{REFERÊNCIAS BIBLIOGRÁFICAS}

\section{Almanaques}

Almanach Americano

de Ross

1931, 1932

Almanack Beirão

1933

Almanack do Biotonico 1934, 1935 1941

Almanach do Capivarol

Almanach do Elixir de Inhame 1934

Almanach Rhodia 1936

Almanach d'A Saúde da Mulher

1932

Almanak Silveira 1914

Galegonal

1937

O Estomago de Crystal 1928 (?)

O Pharol da Medicina 1926, 1934

\section{Bibliografia}

Lobato, Monteiro 1925

Nova, Vera Casa 1996
Rio de Janeiro: The Sydney Ross Co.

Belém (PA): Pharmacia e Drogaria Beirão.

São Paulo: Instituto Medicamenta - Fontoura, Serpe \& Cia.

Rio de Janeiro: Laboratório Capivarol Ltda.

Rio de Janeiro: J. Goulart Machado \& Cia. Ltda.

Rio de Janeiro: Rhodia Brasileira

Rio de Janeiro: Daudt, Oliveira \& Cia. Ltda.

Pelotas (RS): Casa Viúva Silveira \& Filho.

Pelotas (RS): Laboratório do Galegonal.

Norwalk (Conn., EUA): Laboratório Dr. Richards, Dyspesia Tablet Association.

Rio de Janeiro: Granado \& Cia.

Jéca Tatuzinho - edicção especial do Instituto 'Medicamenta'. São Paulo: Fontoura \& Serpe.

Lições de almanaque: um estudo semiótico. Belo Horizonte: Ed. UFMG.

Recebido para publicação em junho de 2005.

Aprovado para publicação em agosto de 2005. 